\title{
Seismic Vulnerability Analysis of Multispan Continuous Bridges Subjected to Mainshock-Aftershock Earthquake Sequences
}

\author{
Yan Liang $(\mathbb{D}$, Yukun Cui, and Chao Ren \\ School of Civil Engineering, Zhengzhou University, Zhengzhou 450001, China \\ Correspondence should be addressed to Yan Liang; liangyan@zzu.edu.cn
}

Received 15 January 2020; Revised 15 March 2020; Accepted 6 June 2020; Published 23 June 2020

Academic Editor: Giuseppe Quaranta

Copyright (c) 2020 Yan Liang et al. This is an open access article distributed under the Creative Commons Attribution License, which permits unrestricted use, distribution, and reproduction in any medium, provided the original work is properly cited.

\begin{abstract}
A multispan continuous 3D bridge model is established on the basis of OpenSees platform, and 160 mainshock-aftershock (MA) sequences are constructed in accordance with the bridge site to study their influence on the seismic vulnerability of bridges. The seismic vulnerability of bridge piers, bearings, and abutments subjected to MA sequences is investigated. The influence of MA sequences on the seismic vulnerability of the bridge system is also analysed using first- and second-order boundary estimation methods. Results show that the seismic response and exceedance probability of the bridge components and system subjected to MA sequences are significantly increased compared with those under the consideration of mainshock only. The second-order boundary estimation method based on component correlation coefficient can significantly reduce the upper and lower limit widths of the vulnerability curves and improve the accuracy. Under the same peak ground acceleration (PGA) and damage state, the exceedance probability of the bridge system is higher than that of any component in the system. The exceedance probability under different damage states of the bridge components and system increases with the PGA. For any given PGA, the exceedance probability decreases with the increase in severity of damage state.
\end{abstract}

\section{Introduction}

As an important hub of the transportation system, a bridge that is damaged in an earthquake will cause not only serious casualties and economic losses but also traffic disruption, thereby affecting the timely implementation of postearthquake rescue works. Therefore, seismic analysis of bridges is essential. The definition of vulnerability analysis is the failure probability of structures under different disaster levels. Vulnerability analysis, as an important means of seismic analysis, mainly refers to the possibility of different damage degrees of bridges under different earthquake intensities. This method quantitatively describes the seismic performance of bridges from the perspective of probability and macroscopically reflects the relationship between earthquake intensity and structural damage state. Vulnerability analysis is widely used for the determination of weak links of bridges, seismic strengthening, and risk assessment.

In recent years, seismic vulnerability analysis of bridges is currently generated based on an initially undamaged bridge condition that is subjected to only one seismic record [1]. In actual earthquakes, after the mainshock, a large number of aftershocks will usually occur [2]. Under a strong mainshock, most damaged structures will enter the plastic state, and the strength, stiffness, and seismic performance of the structures will degenerate [3]. When subjected to strong aftershocks, the degree of structural damage will increase significantly. Although several scholars have performed relevant studies on the effect of MA sequences on bridge structures, most of these studies are confined to the component level, and few studies have been conducted on the bridge system [4]. Therefore, studying the seismic performance of bridges subjected to MA sequences is important.

In the present study, 160 seismic records based on site conditions are initially selected, and 160MA sequences are constructed in accordance with the Gutenberg-Richter rule and Joyner-Boore empirical formula. On the basis of the damage index of each component, incremental dynamic analysis (IDA) is used to study the seismic vulnerability of bridge components subjected to mainshock and MA 
sequences [5]. On the basis of structural reliability theory, first- and second-order boundary estimation methods are used to draw the vulnerability curves of the bridge system subjected to mainshock and MA sequences.

\section{Bridge Modeling}

The example bridge in this study is a six-span $(6 \times 60 \mathrm{~m}=360 \mathrm{~m})$ prestressed concrete rigid-frame continuous bridge (Figure 1); the superstructure of the bridge is a box girder with equal height $(3.35 \mathrm{~m})$, single box, and single cell (Figure 2(a)). The $1^{\#}$ bearing (left abutment top) and $5^{\#}$ bearing (right abutment top) are QZ6000 spherical bearings; the $2^{\#}$ bearing ( $1^{\#}$ pier top), $3^{\#}$ bearing ( $4^{\#}$ pier top), and $4^{\#}$ bearing ( $5^{\#}$ pier top) are QZ12500 spherical bearings; the $2^{\#}$ pier and $3^{\#}$ pier are rigid-frame piers (Figure $2(\mathrm{~b})$ ). The foundation of piers is weak weathered rock, and $1.5 \mathrm{~m}$ thick spread foundations are adopted. The main girder, $2^{\#}$ pier, and $3^{\#}$ pier are made of concrete C50; the $1^{\#}, 4^{\#}$, and $5^{\#}$ piers are made of concrete $\mathrm{C} 40$; the spread foundations are made of concrete C25.

The actual seismic damage statistics show that the possibility of plastic deformation of bridge superstructures under earthquake is small [6]. In the aseismatic design of a bridge, the assumption is that piers initially enter the plastic state, and the plastic hinges are produced to consume earthquake energy to ensure the safety of the main girders. Therefore, when studying the response of a bridge under earthquake, the main girders are supposed to be in the elastic state. This study adopts the elastic beam column element to simulate the main girders. The mass of unit length includes the dead weight and secondary loading.

Nonlinear beam column element in OpenSees material library is selected to simulate the plastic deformation of piers. Concrete piers include confined concrete in the core area and unconstrained concrete. Concrete01 model (Figure 3(a)) considering the restraint effect of stirrups is used to simulate the constitutive relationship of concrete [7]. The constitutive relationship of rebars is simulated by Steel02 model (Figure 3(b)) which is a double-broken-line model.

The bridge adopts spherical bearings, which are a special type of pot bearings consisting of top board, bottom board, a convex intermediate plate, and two different shapes of polytetrafluoroethylene (PTFE) boards. The displacement is realised by the sliding between the top and bottom boards, and the rotation is achieved by the sliding between the spherical board and spherical PTFE board. The sliding mechanism and sliding friction coefficient are the same as those of the pot bearings; the hysteretic response is shown in Figure 4(a). Thus, nonlinear connecting element is adopted to simulate spherical bearings.

In seismic vulnerability analysis of bridge abutments, the transverse seismic response of bridge abutments is not considered, and seismic records are input along the longitudinal bridge direction. Equivalent springs are used in this study to simulate abutments. Assuming that the transverse stiffness of abutments is infinite, the vertical constraints of abutments are simulated by using Hyperbolic Gap Material in OpenSees platform database [8]; the constitutive model of Hyperbolic Gap Material is shown in Figure 4(b).

As the bridge foundations are spread foundations, the bottom of piers is assumed to be consolidated during modeling.

\section{Analysis of the Damage Index of Bridge Components}

Under the action of earthquake, the reinforced concrete bridge piers usually occur bending failure. The displacement ductility ratio is used to define the damage state of piers, as shown in Table 1 [9].

In Table $1, \mu$ is the relative displacement ductility ratio of piers, $\mu_{\text {cyl } 1}$ is the displacement ductility ratio of piers at the first yield of longitudinal reinforcement, $\mu_{\mathrm{cy}}$ is the displacement ductility ratio of piers at the equivalent yield of the pier section, $\mu_{\mathrm{c} 4}$ is the displacement ductility ratio when the pier concrete compressive strain reaches 0.004 , and $\mu_{\mathrm{cmax}}$ is the maximum displacement ductility ratio of piers.

The critical values of different damage states must be initially determined to identify the damage state of piers under earthquake. Firstly, the moment-curvatures of the pier section (Figure 5) are analysed to obtain the calculation parameters of damage index (Table 2), and then the critical values of different damage states are obtained based on the height of piers.

The calculation process of damage index of bridge piers under different limit damage states is shown in equations (1) to (6) [10]; the damage index of piers is shown in Table 3.

$$
\begin{aligned}
u & =\frac{\Delta}{\Delta_{c y l}}, \\
\mu_{\mathrm{cy} 1} & =\frac{\Delta_{\mathrm{cyl}}}{\Delta_{\mathrm{cy} 1}}=1, \\
\mu_{\mathrm{cy}} & =\frac{\Delta_{\mathrm{cy}}}{\Delta_{\mathrm{cy} 1}}=\frac{(1 / 3) \phi_{\mathrm{y}} L^{2}}{(1 / 3) \phi_{\mathrm{y}}^{\prime} L^{2}}=\frac{\phi_{\mathrm{y}}}{\phi_{\mathrm{y}}}, \\
\Delta_{\mathrm{c} 4} & =\Delta_{\mathrm{cy}}+\Delta_{\mathrm{p} 4}=\frac{1}{3} \phi_{\mathrm{y}} L^{2}+L_{\mathrm{P}} \phi_{\mathrm{P}}\left(L-\frac{L_{\mathrm{P}}}{2}\right), \\
\mu_{\mathrm{c} 4} & =\frac{\Delta_{\mathrm{c} 4}}{\Delta_{\mathrm{cy} 1}}, \\
\mu_{\mathrm{c} \max } & =\mu_{\mathrm{c} 4}+3 .
\end{aligned}
$$

$\phi_{\mathrm{y}}^{\prime}$ is the curvature of tensile reinforcement at the first yield, $\phi_{\mathrm{y}}$ is the equivalent yield curvature, $\Delta$ is the relative displacement of the pier top under earthquake, $\Delta_{\text {cyl } 1}$ is the relative displacement of the pier top at the first yield of longitudinal reinforcement, $\phi_{\mathrm{p}}$ is the maximum plastic curvature of the section within the equivalent plastic hinge length, $L$ is the distance between the plastic hinge and inflection point, $L_{\mathrm{p}}$ is the equivalent plastic hinge length, and $\Delta_{c 4}$ is the relative displacement of the pier top when concrete compressive strain reaches 0.004 . 


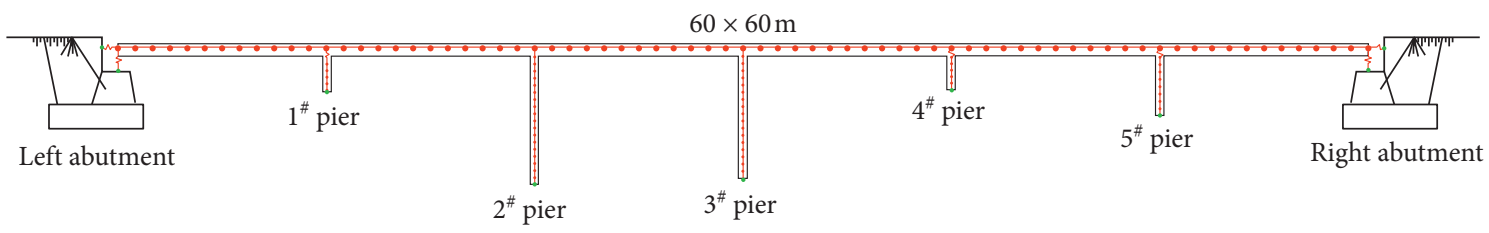

FIgURE 1: Full-bridge facade layout.
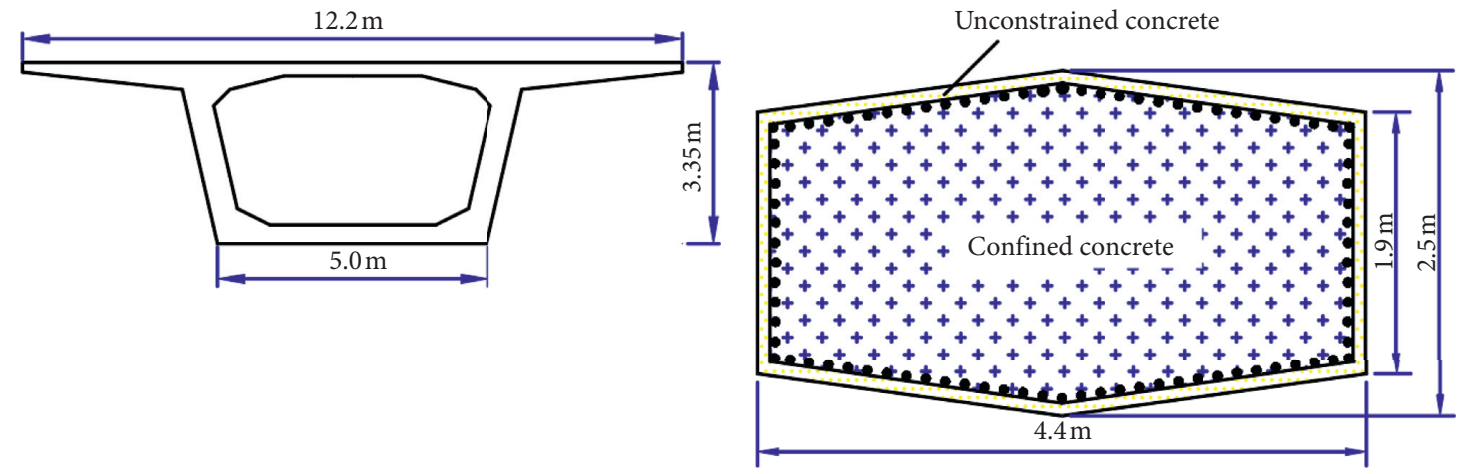

(a)

(b)

Figure 2: Bridge components cross section. (a) Girder section. (b) Pier section.

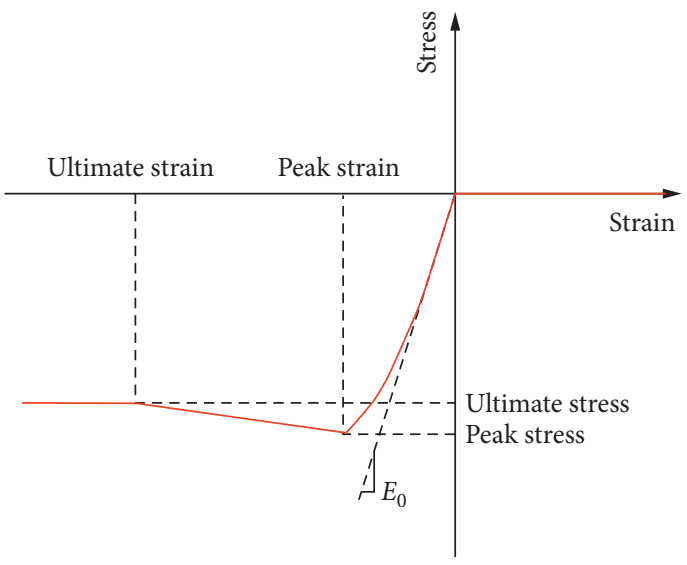

(a)

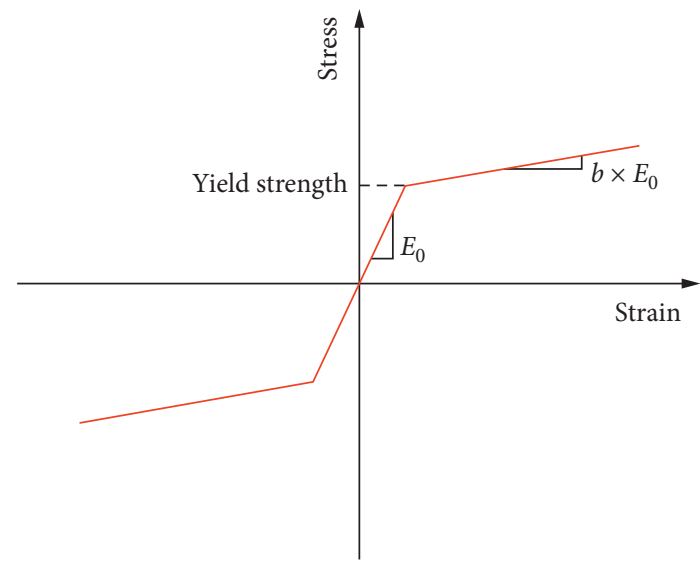

(b)

FIgURE 3: Material parameters. (a) Concrete01 model. (b) Steel02 model.

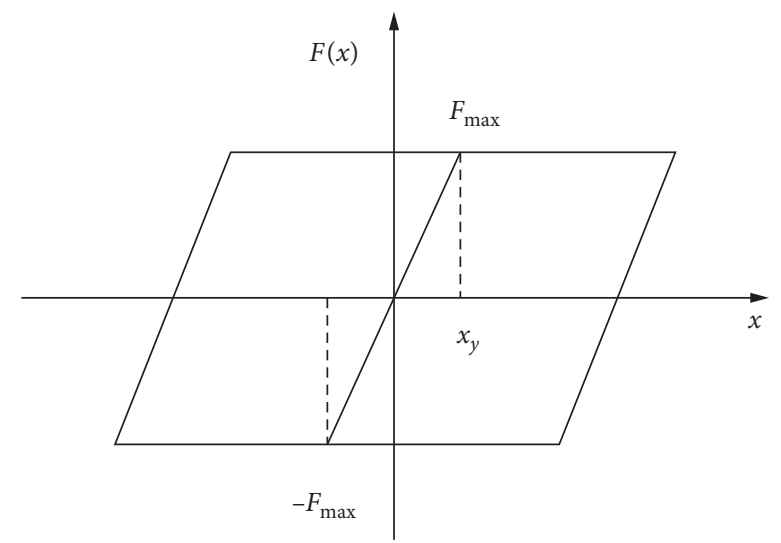

(a)

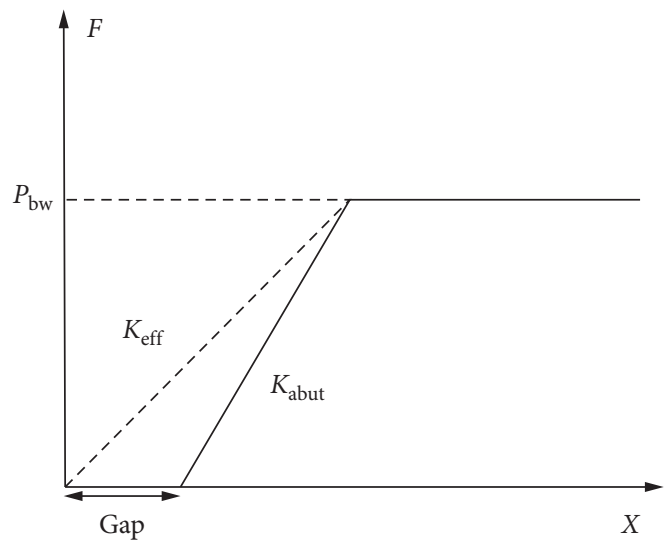

(b)

Figure 4: Simulation of bridge components. (a) Hysteretic response of bridge bearings. (b) Constitutive model of Hyperbolic Gap Material. 
TABle 1: Damage state of piers.

\begin{tabular}{|c|c|c|c|c|c|}
\hline Damage state & Basic integrity & Slight damage & Moderate damage & Extensive damage & Complete damage \\
\hline Failure criterion & $\mu \leq \mu_{\mathrm{cyl}}$ & $\mu_{\mathrm{cy} 1} \leq \mu \leq \mu_{\mathrm{cy}}$ & $\mu_{\mathrm{cy}} \leq \mu \leq \mu_{\mathrm{c} 4}$ & $\mu_{\mathrm{c} 4} \leq \mu \leq \mu_{\mathrm{cmax}}$ & $\mu_{\mathrm{c} \max } \leq \mu$ \\
\hline
\end{tabular}

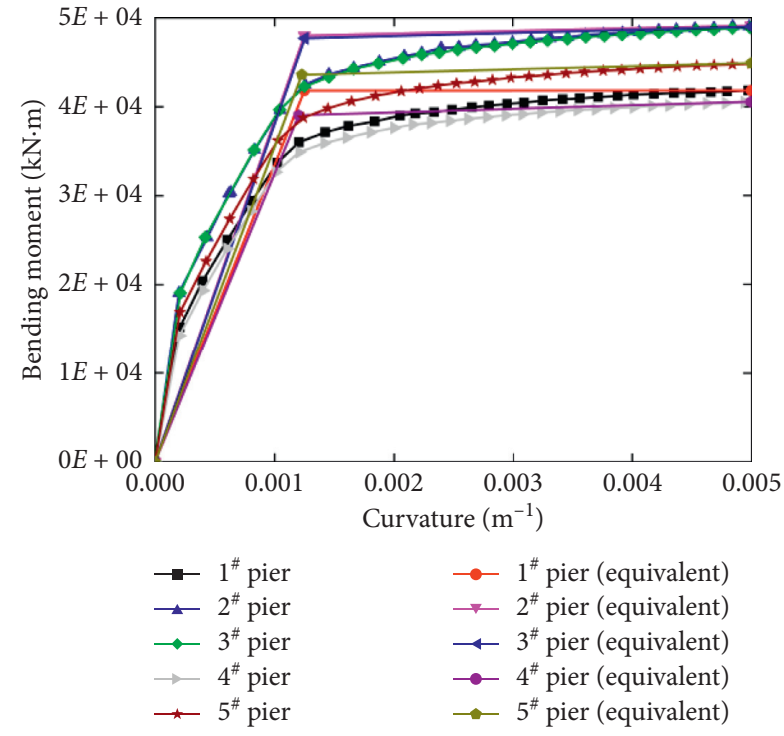

Figure 5: The moment-curvature curves of pier section.

TABLe 2: Calculation parameters of the damage index of piers.

\begin{tabular}{lllccc}
\hline Number of pier & $\phi_{\mathrm{y}}^{\prime}\left(\mathrm{m}^{-1}\right)$ & $\phi_{\mathrm{y}}\left(\mathrm{m}^{-1}\right)$ & $\Delta_{\text {cyl }}(\mathrm{m})$ & $\Delta_{\text {cy }}(\mathrm{m})$ & $\Delta_{\mathrm{c} 4}(\mathrm{~m})$ \\
\hline $1^{\#}$ & 0.001010 & 0.001211 & 0.0315 & 0.0378 & 0.0468 \\
$2^{\#}$ & 0.001039 & 0.001250 & 0.2299 & 0.2766 & 0.2934 \\
$3^{\#}$ & 0.001038 & 0.001249 & 0.2128 & 0.2560 & 0.2678 \\
$4^{\#}$ & 0.001002 & 0.001200 & 0.0281 & 0.0336 & 0.0417 \\
$5^{\#}$ & 0.001029 & 0.001235 & 0.0939 & 0.1128 & 0.1368 \\
\hline
\end{tabular}

TABle 3: Damage index of piers.

\begin{tabular}{lccccc}
\hline Number of pier & Pier height $(\mathrm{m})$ & $\mu_{\mathrm{cy} 1}$ & $\mu_{\mathrm{cy}}$ & $\mu_{\mathrm{c} 4}$ & $\mu_{\mathrm{cmax}}$ \\
\hline $1^{\#}$ & 9.68 & 1 & 1.199 & 1.486 & 4.486 \\
$2^{\#}$ & 36.44 & 1 & 1.203 & 1.276 & 4.276 \\
$3^{\#}$ & 35.07 & 1 & 1.203 & 1.258 & 4.258 \\
$4^{\#}$ & 9.17 & 1 & 1.198 & 1.484 & 4.484 \\
$5^{\#}$ & 16.55 & 1 & 1.200 & 1.457 & 4.457 \\
\hline
\end{tabular}

Previous bridge seismic damage showed that the vulnerability of bearings is considerably greater than that of other components under earthquake. Related researches $[11,12]$ recommended that the relative displacement values of $37,104,136$, and $187 \mathrm{~mm}$ are the critical values of the slight, moderate, extensive, and complete damage of spherical bearings, respectively.

Abutments are important components of bridges; they support the bridge superstructures and connect with embankment. Previous seismic damage statistics have shown that abutments are vulnerable components of bridges and will deform, crack, and even break vertically under earthquakes. Park and Ang [13] set $50 \mathrm{~mm}$ displacement of abutments as the limit value of the moderate damage of abutments. On this basis, 25, 100, and $150 \mathrm{~mm}$ displacements are used as the critical values of the slight, extensive, and complete damage of abutments, respectively.

\section{Construction of MA Sequences}

The number of MA sequences in the seismic database at present is relatively small. In order to ensure the accuracy of vulnerability analysis results, sufficient seismic records should be input into the finite element model for a large amount of nonlinear dynamic analysis. Therefore, the MA sequences are constructed through artificial synthesis method in this study.

4.1. Determination of Time Interval. A total of 160 natural seismic records fit for the bridge site with epicentral distance greater than $20 \mathrm{~km}$ are selected from the Pacific Earthquake Engineering Research Center (PEER) to reflect the uncertainty of seismic records fully and ensure the accuracy of calculation results [14]. PGA is used as the ground motion parameter for seismic vulnerability analysis of bridges in this paper [15]; the histogram of the PGA frequency of the selected 160 natural seismic records is shown in Figure 6.

In actual earthquakes, aftershocks usually act on structures again when they are static after the mainshock. When constructing the MA sequences, if no time interval exists between the mainshock and aftershock or the time interval is excessively short, structures have not been still at the beginning of the aftershock, which is inconsistent with the actual earthquakes. If the time interval between the mainshock and aftershock is considerably large, the time consumption of nonlinear time history analysis of structures will increase greatly, and the computational efficiency will be affected. Therefore, the reasonable time interval of the mainshock and aftershock should be used to simulate the MA sequences accurately. The time required for the same bridge component to return to static state after different seismic records is approximately the same. Three representative seismic records are selected to study the minimum time required for all bridge components to return to static state after the earthquake; the detailed information of selected seismic records is shown in Table 4.

Artificial seismic record with zero acceleration of $70 \mathrm{~s}$ after each natural seismic record is used to simulate the free vibration of structures after earthquake. Long free vibration time leads to a small response of structures due to the existence of damping, and structures finally tend to be still. The maximum responses of structures under free vibration at 10 , $15,30,35,45$, and $60 \mathrm{~s}$ are compared to examine the attenuation law of the response of structures under free vibration after the earthquake. Three artificial seismic records are input into the model to study the variation in structural 


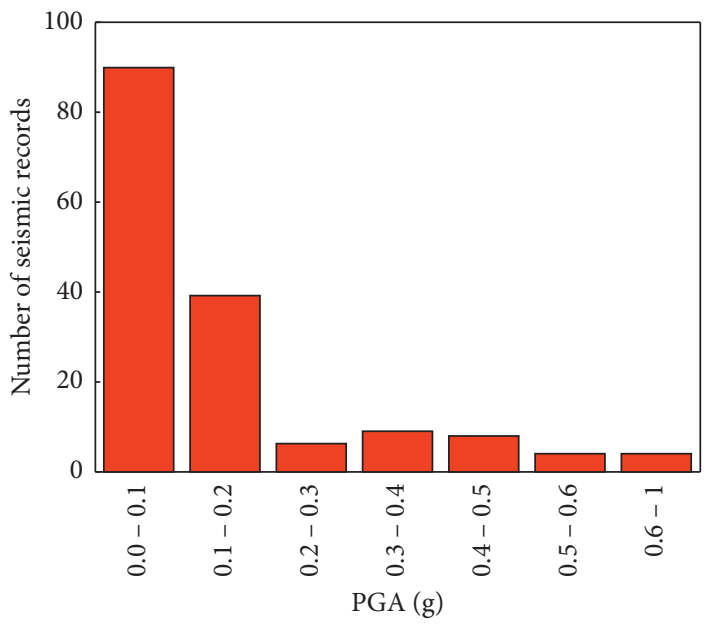

FIgURE 6: The histogram of the PGA frequency.

TABLE 4: Detailed information of selected seismic records.

\begin{tabular}{|c|c|c|c|c|c|c|}
\hline Number & Earthquake event & Station name & Time & Magnitude & Earthquake duration (s) & PGA (g) \\
\hline $1^{\#}$ & Loma Prieta & RSN806 & $10 / 18 / 1989$ & 7.1 & 39.3 & 0.207 \\
\hline $2^{\#}$ & Northridge & RSN1003 & $1 / 17 / 1994$ & 6.6 & 31.6 & 0.431 \\
\hline $3^{\#}$ & Chi-Chi & RSN1231 & $9 / 20 / 1999$ & 7.6 & 90.0 & 0.602 \\
\hline
\end{tabular}

response under free vibration, and the calculation results are shown in Table 5 and Figure 7.

Table 5 and Figure 7 show that the structural response decreases rapidly with the extension of free vibration time. When the free vibration time is $35 \mathrm{~s}$, the relative displacement between the left abutment and postearthquake position is only $0.001 \mathrm{~mm}$, which is less than $1 / 100000$ of the maximum seismic response. Other components have similar laws.

In summary, a large time interval between the mainshock and aftershock results in real MA sequences to be simulated. However, if the time interval is excessively large, the computational efficiency will be significantly reduced. The time interval between the mainshock and aftershock considering the two factors comprehensively is $35 \mathrm{~s}$. At this time, the response of structures relative to the postearthquake position is only $1 / 100000$ of the maximum response under the earthquake. The structures are approximated to be in a static state, which can not only simulate the actual earthquakes but also ensure the calculation efficiency.

4.2. Peak Acceleration of MA Sequences. Hatzigeorgiou and Beskos [16] proposed that MA sequences can be constructed by repeated method, which determines the seismic frequency and the peak acceleration adjustment coefficient of MA sequences in accordance with the Gutenberg-Richter rule and Joyner-Boore empirical formula. The Gutenberg-Richter rule indicates that the relationship between the magnitude and number of earthquakes occurring in any region and time period can be calculated from the following expression:

$$
N=10^{A-B M}
$$

where $M$ is the earthquake magnitude, $N$ is the number of earthquakes with the magnitude $M, A$ is the number of earthquakes in this region, and $B$ is usually equal to 1 .

Constant $B$ can also be applied to the region between the mainshock and the foreshock and aftershock [17]. As $A$ and $B$ are both constants and $B$ equals 1 , the relationship between $N_{1}$ earthquakes with magnitude $M_{1}$ and $N_{2}$ earthquakes with magnitude $M_{2}$ in the same area is given as follows:

$$
M_{1}+\log \left(N_{1}\right)=M_{2}+\log \left(N_{2}\right) \text {. }
$$

Equation (8) implies that when an earthquake with magnitude $M$ occurs in an area, two aftershocks with magnitude $M-0.301$ will occur in the area. The Joyner-Boore empirical formula presents that the relationship between the earthquake magnitude and peak acceleration can be taken equal to the following equation:

$$
\log (P G A)=0.49+0.23(M-6)-\log \left(\sqrt{R^{2}+8^{2}}\right)-0.0027 \sqrt{R^{2}+8^{2}}
$$


TABLE 5: Free vibration response of bridge components.

\begin{tabular}{|c|c|c|c|c|c|c|}
\hline \multirow[b]{2}{*}{$\begin{array}{l}\text { Free vibration time } \\
\text { (s) }\end{array}$} & \multicolumn{2}{|c|}{$1^{\#}$ artificial seismic record } & \multicolumn{2}{|c|}{$2^{\#}$ artificial seismic record } & \multicolumn{2}{|c|}{$3^{\#}$ artificial seismic record } \\
\hline & $\begin{array}{l}\text { Displacement of } \\
\text { the } 1^{\#} \text { pier top } \\
(\mathrm{mm})\end{array}$ & $\begin{array}{c}\text { Displacement of } \\
\text { the } 4^{\#} \text { pier top } \\
(\mathrm{mm})\end{array}$ & $\begin{array}{c}\text { Displacement of } \\
\text { the } 4^{\#} \text { bearing } \\
(\mathrm{mm})\end{array}$ & $\begin{array}{l}\text { Displacement of } \\
\text { left abutment } \\
(\mathrm{mm})\end{array}$ & $\begin{array}{c}\text { Displacement of } \\
\text { the } 3^{\#} \text { pier top } \\
(\mathrm{mm})\end{array}$ & $\begin{array}{c}\text { Bending } \\
\text { moment of the } \\
2^{\#} \text { pier bottom } \\
(\mathrm{kN} \cdot \mathrm{m})\end{array}$ \\
\hline 0 & 0.342 & 0.306 & 0.739 & 4.786 & 1.161 & 830.480 \\
\hline 15 & 0.076 & 0.049 & 0.130 & 0.915 & 0.584 & 526.018 \\
\hline 30 & 0.067 & 0.039 & 0.112 & 0.797 & 0.563 & 515.162 \\
\hline 35 & 0.067 & 0.039 & 0.111 & 0.794 & 0.563 & 514.950 \\
\hline 45 & 0.067 & 0.039 & 0.111 & 0.793 & 0.562 & 514.858 \\
\hline 60 & 0.067 & 0.039 & 0.111 & 0.793 & 0.562 & 514.848 \\
\hline $\begin{array}{l}\text { Postearthquake } \\
\text { position }\end{array}$ & 0.067 & 0.039 & 0.111 & 0.793 & 0.562 & 514.848 \\
\hline $\begin{array}{l}\text { Maximum response } \\
\text { under earthquake }\end{array}$ & 45.356 & 45.847 & 124.294 & 125.129 & 286.237 & 42164.100 \\
\hline
\end{tabular}

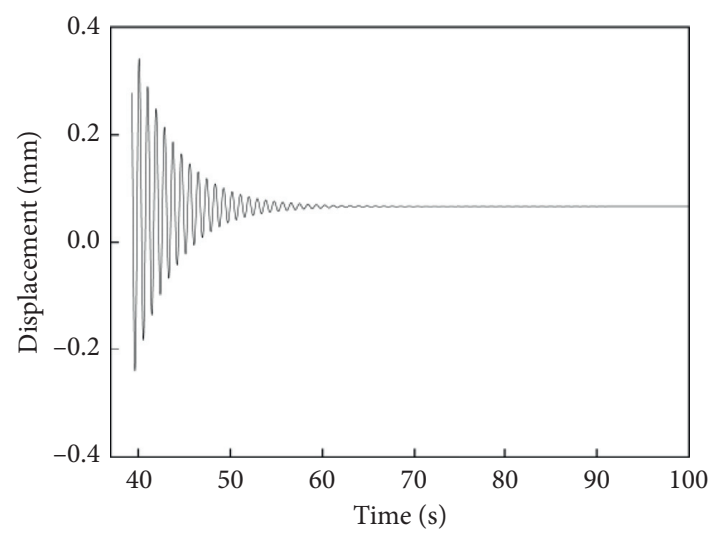

(a)

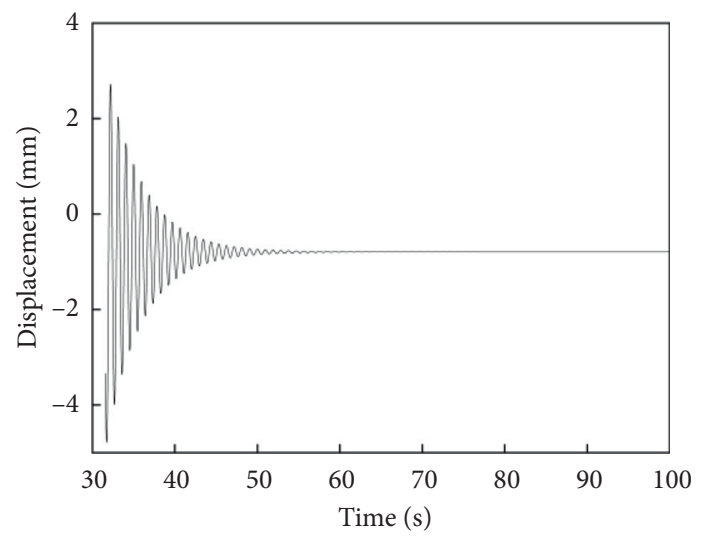

(b)

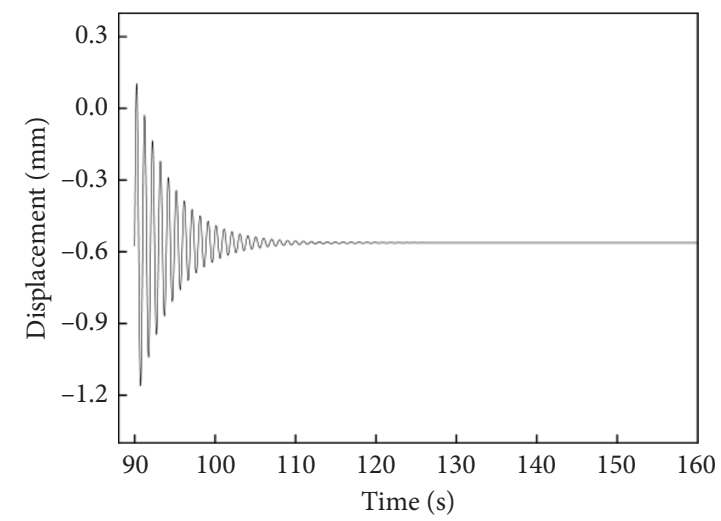

(c)

FiguRE 7: Free vibration response of bridge components. (a) Displacement of the $1^{\#}$ pier top. (b) Displacement of left abutment. (c) Displacement of the $3^{\#}$ pier top.

where $R$ is the epicentral distance and the unit is $\mathrm{km}$.

On the basis of equations (8) and (9), the relationship between the peak accelerations of the aftershock and mainshock can be derived as

$$
\begin{aligned}
\frac{\operatorname{PGA}_{(2)}}{\mathrm{PGA}_{(1)}} & =\frac{10^{0.49+0.23(M-0.301-6)-\log \left(\sqrt{R^{2}+8^{2}}\right)-0.0027 \sqrt{R^{2}+8^{2}}}}{10^{0.49+0.23(M-6)-\log \left(\sqrt{R^{2}+8^{2}}\right)-0.0027 \sqrt{R^{2}+8^{2}}}} \\
& =10^{-0.06923}=0.8526 .
\end{aligned}
$$


Therefore, for an earthquake with peak acceleration of $A$, two earthquakes with peak acceleration of $0.8526 A$ will occur. To sum up, this study adjusts the seismic acceleration of 160 seismic records to $0.8526,1$, and 0.8526 to construct the foreshock-mainshock-aftershock sequences considering the effect of foreshocks and aftershocks on the seismic performance of bridges.

\section{Seismic Vulnerability Analysis Method}

Seismic vulnerability refers to the exceedance probability of a certain limit state of a structure under different intensities of ground motion [18] as follows:

$$
P_{f}=P[D \geq C \mid \mathrm{IM}] \text {, }
$$

where IM represents the ground motion parameters, $D$ is the seismic response of structures corresponding to the structural demand, and $C$ is the structural damage index corresponding to the structural capacity.

Seismic vulnerability curve is a set of curves drawn with the seismic intensity index as abscissa and the exceedance probability of structural components or system as ordinate. Seismic vulnerability function can be expressed by structural bearing capacity and seismic demand as

$$
P_{f}=P_{r}\left(\frac{S_{c}}{S_{d}} \leq 1\right)=P_{r}\left(\ln \left(\frac{S_{c}}{S_{d}}\right) \geq 0\right),
$$

where $S_{c}$ is the structural capacity and $S_{d}$ is the structural demand.

On the basis of classical reliability theory, structural capacity and structural demand are often assumed to obey the lognormal distribution of two parameters $[19,20]$ as follows:

$$
\begin{aligned}
& S_{c}=\ln \left(\mu_{c}, \beta_{c}\right), \\
& S_{d}=\ln \left(\mu_{d}, \beta_{d}\right),
\end{aligned}
$$

where $\mu_{c}$ and $\beta_{c}$ represent the mean and logarithmic standard deviation of the seismic capacity of structures, respectively, and $\mu_{d}$ and $\beta_{d}$ represent the mean and logarithmic standard deviation of structural seismic demand, respectively.

On the basis of equations (12) and (13), the seismic vulnerability function can be transformed into a standard normal distribution as follows:

$$
P_{f}=\Phi\left(\frac{\ln \mu_{d}-\ln \mu_{c}}{\sqrt{\beta_{c}^{2}+\beta_{d}^{2}}}\right) .
$$

Cornell et al. [21] assumed that the mean value of earthquake demand parameter is exponentially related to the ground motion parameters, as shown in equation (15). The probabilistic demand model is obtained by obtaining logarithms from both sides of equation (15), as shown in equation (16).

$$
\begin{gathered}
\mu_{d}=a \cdot \mathrm{IM}^{b}, \\
\ln \left(\mu_{d}\right)=b \cdot \ln (I M)+\ln a,
\end{gathered}
$$

where $a$ and $b$ are constants. The seismic vulnerability function can be obtained by introducing equation (16) into equation (14) as follows:

$$
P_{f}=\Phi\left(\frac{\ln a+b \ln (\mathrm{IM})-\ln \mu_{c}}{\sqrt{\beta_{c}^{2}+\beta_{d}^{2}}}\right) .
$$

When PGA is used as the ground motion intensity index, $\sqrt{\beta_{c}^{2}+\beta_{d}^{2}}$ is $0.5[22]$.

\section{Seismic Vulnerability Analysis of Bridge Components}

6.1. Seismic Vulnerability Analysis of Bridge Piers. The cross section form and material of $1^{\#}$ pier and $4^{\#}$ pier are the same, and the difference of pier height is not significant, so the vulnerability curves of $1^{\#}$ pier and $4^{\#}$ pier are basically the same. The cross section form and material of $2^{\#}$ pier and $3^{\#}$ pier are also the same, and the difference of pier height is not significant, so the vulnerability curves of $2^{\#}$ pier and $3^{\#}$ pier are basically the same. In this study, the $1^{\#}, 2^{\#}$, and $5^{\#}$ piers are selected to study the effect of MA sequences on vulnerability of bridge piers. The relative displacement ductility ratio of piers under earthquake and corresponding PGA is analysed by logarithmic regression analysis on the basis of the time-history analysis results of 160 natural seismic records and $160 \mathrm{MA}$ sequences, and the analysis results are shown in Figure 8.

The vulnerability function of bridge piers subjected to mainshock and MA sequences is obtained by substituting the probabilistic demand models for the seismic response of bridge piers subjected to mainshock and MA sequences into equation (17). The exceedance probability of piers under different damage states can be calculated on the basis of the expression of vulnerability function. With PGA as abscissa and the exceedance probability as ordinate, the vulnerability curves for piers subjected to mainshock and MA sequences are drawn, as shown in Figure 9. For the convenience of marking in the figures, $\mathrm{LS}_{1}, \mathrm{LS}_{2}, \mathrm{LS}_{3}$, and $\mathrm{LS}_{4}$ are used to represent the four limit states of slight, moderate, extensive, and complete damage, respectively.

Figure 9 depicts that the exceedance probability of bridge piers under different damage states increases with the increase in PGA. For any given PGA, the exceedance probability decreases with the increase in severity of damage state. When the maximum peak accelerations of the mainshock and MA sequences are the same, under the same damage state, the exceedance probability of the $1^{\#}$ pier is the highest, that of the $5^{\#}$ pier is the second, and that of the $2^{\#}$ pier is the smallest. The main reason is that the $2^{\#}$ pier is a rigid-frame pier, and the concrete strength grade is high (C50). In addition, the $2^{\#}$ pier has the greatest height and a great ductile deformation capacity.

Under the same PGA, the bridge piers are more vulnerable to MA sequences than to the mainshock. When PGA is equal to 0.4 , the exceedance probabilities of the four damage states subjected to MA sequences of the $1^{\#}$ pier increase by $4.2 \%, 6.1 \%, 8.7 \%$, and $28.3 \%$ compared with the 


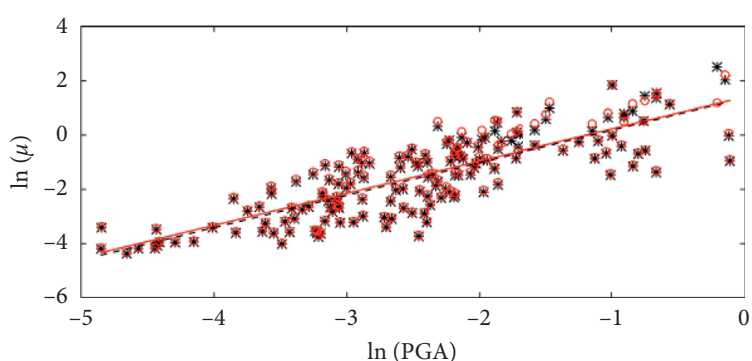

- Data of MA sequences Fitting line of MA sequences

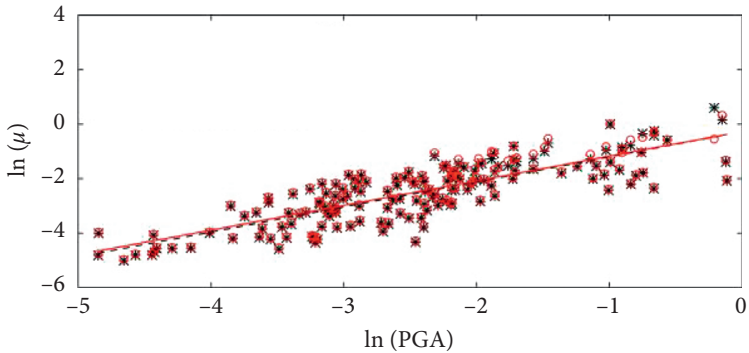

- Data of MA sequences

Fitting line of MA sequences

* Data of mainshock

- - - Fitting line of mainshock

(a)

(b)

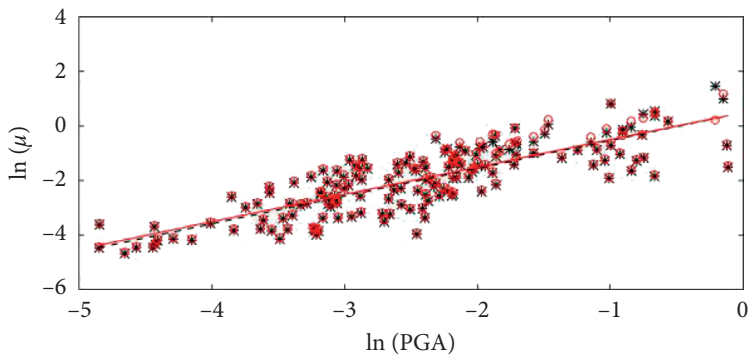

- Data of MA sequences * Data of mainshock

_ Fitting line of MA _ _- Fitting line of mainshock

(c)

Figure 8: Regression analysis of the seismic demand. (a) $1^{\#}$ pier. (b) $2^{\#}$ pier. (c) $5^{\#}$ pier.

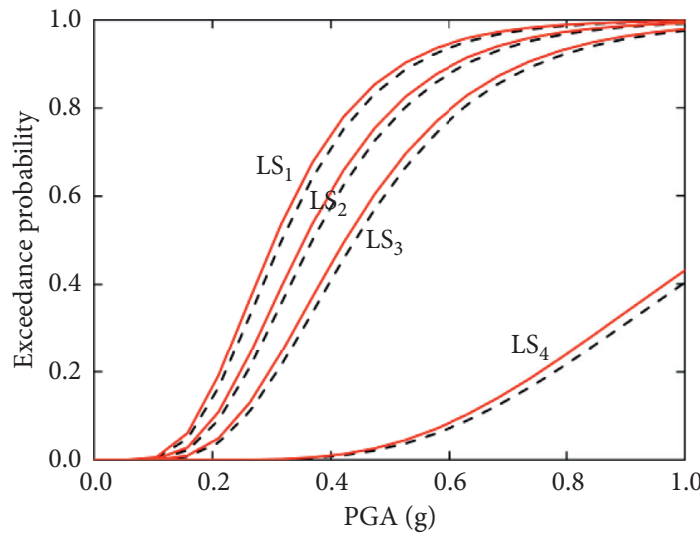

- MA sequences

_. - Mainshock

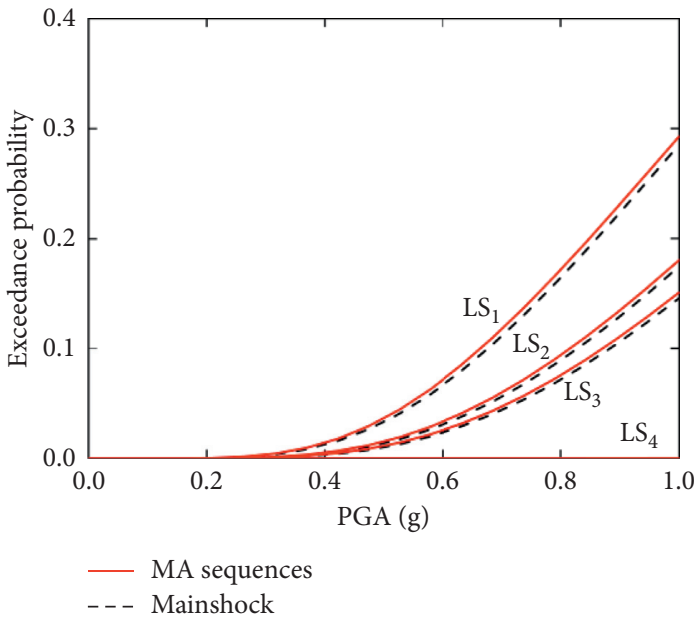

(b)

(a)

Figure 9: Continued. 


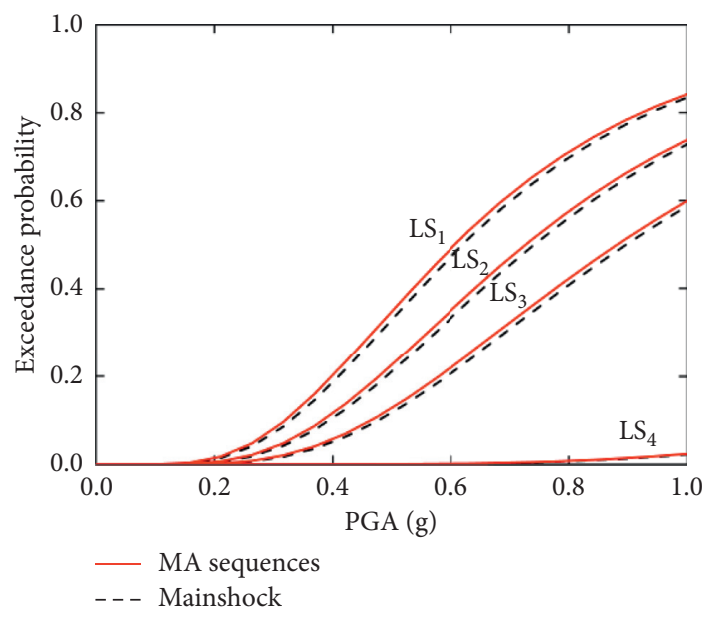

(c)

Figure 9: Vulnerability curves. (a) $1^{\#}$ pier. (b) $2^{\#}$ pier. (c) $5^{\#}$ pier.

mainshock; those under the MA sequences of the $2^{\#}$ pier increase by $13.4 \%, 15.3 \%, 15.9 \%$, and $29.8 \%$ compared with the mainshock; those under the MA sequences of the $5^{\#}$ pier increase by $8.5 \%, 10.4 \%, 12.5 \%$, and $26.7 \%$ compared with the mainshock.

When PGA is equal to 0.4, under the condition of slight, extensive, and complete damage, the exceedance probabilities of three piers subjected to MA sequences increase by $8.7 \%, 12.4 \%$, and $28.3 \%$ on average compared with those subjected to the mainshock. The main reason is that, under the condition of slight damage, the seismic response of piers is maintained within the elastic range, and the secondary damage caused by the aftershock to the piers is insignificant. Under the condition of extensive and complete damages, the secondary damage caused by aftershocks to the damaged structure is significant. When evaluating the seismic performance of concrete piers, the influence of aftershocks on piers should be considered.

6.2. Seismic Vulnerability Analysis of Bridge Bearings. The seismic vulnerability curves for the $1^{\#}$ and $5^{\#}$ bearings on both sides are the same due to the same abutment structure and bearing type (QZ6000). The type of the $2^{\#}$ and $3^{\#}$ bearings is the same, the pier height is close, and the seismic vulnerability curves are also roughly the same. In this study, representative $1^{\#}, 2^{\#}$, and $4^{\#}$ bearings are selected to evaluate the vulnerability of bearings subjected to mainshock and MA sequences. Consistent with the above procedure of vulnerability analysis of bridge piers, the vulnerability curves for bridge bearings subjected to mainshock and MA sequences are obtained, as shown in Figure 10.

Figure 10 illustrates that the exceedance probability under different damage states of bearings increases with the increase in PGA. Under the same PGA and damage state, the exceedance probability of the $1^{\#}$ bearing is the largest, that of the $2^{\#}$ bearing is the second, and that of the $4^{\#}$ bearing is the smallest. The main reasons are that the $1^{\#}$ bearing type is QZ6000, the $2^{\#}$ and $4^{\#}$ bearing type is QZ12500, the $2^{\#}$ and $4^{\#}$ bearings bear greater upper structure gravity and sliding friction force, and the horizontal seismic force required for the $2^{\#}$ and $4^{\#}$ bearings to reach critical displacement is larger than that for the $1^{\#}$ bearing. Considering the greater height of the $5^{\#}$ pier, the ductility of the $5^{\#}$ pier can consume additional seismic energy and transfer less energy to the bearing; hence, the exceedance probability of the $4^{\#}$ bearing is the smallest.

Under the same PGA and damage state, the bridge bearings are more vulnerable to MA sequences than to the mainshock. When PGA is equal to 0.4 , the exceedance probabilities of the four damage states subjected to MA sequences of the $1^{\#}$ bearing increase by $0.8 \%, 9.5 \%, 13.7 \%$, and $19.3 \%$ compared with the mainshock; those subjected to MA sequences of the $2^{\#}$ bearing increase by $1.6 \%, 11.8 \%$, $15.8 \%$, and $21.1 \%$ compared with the mainshock; those subjected to MA sequences of the $4^{\#}$ bearing increase by $4.1 \%, 18.2 \%, 23.1 \%$, and $29.5 \%$ compared with the mainshock.

6.3. Seismic Vulnerability Analysis of Bridge Abutments. In accordance with the above vulnerability analysis procedure of piers, the vulnerability analysis of abutments is carried out, and the results are shown in Figure 11.

Figure 11 depicts that the exceedance probability under different damage states of abutments increases with the increase in PGA. Under the same PGA and damage state, the exceedance probabilities of abutments on both sides are the same. The main reason is that the abutments on both sides have the same structure and damage index, and the seismic responses of the abutments are the same.

Under the same PGA, the bridge abutments are more vulnerable to MA sequences than to the mainshock. When PGA is equal to 0.4 , the exceedance probabilities of the four damage states subjected to MA sequences of the left abutment increase by $0.1 \%, 2.2 \%, 9.3 \%$, and $15.7 \%$ compared with the mainshock; those subjected to MA sequences of the right abutment increase by $0.2 \%, 2.4 \%, 10.0 \%$, and $16.9 \%$ compared with the mainshock. 


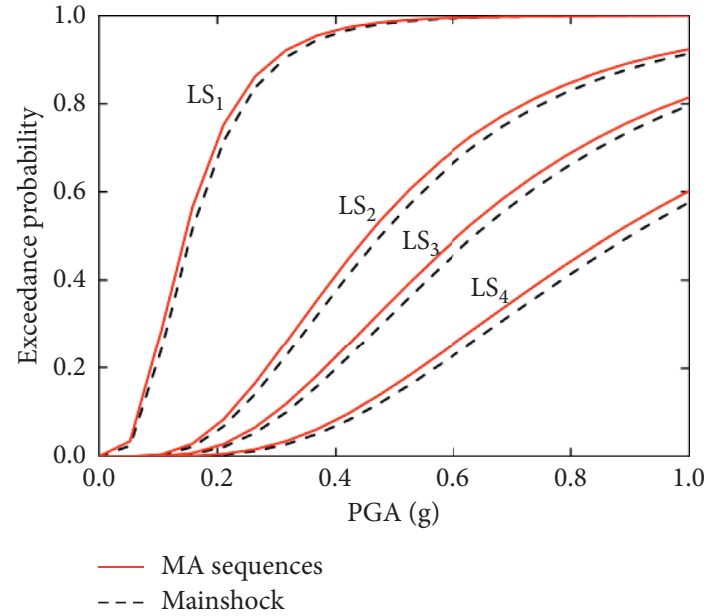

(a)

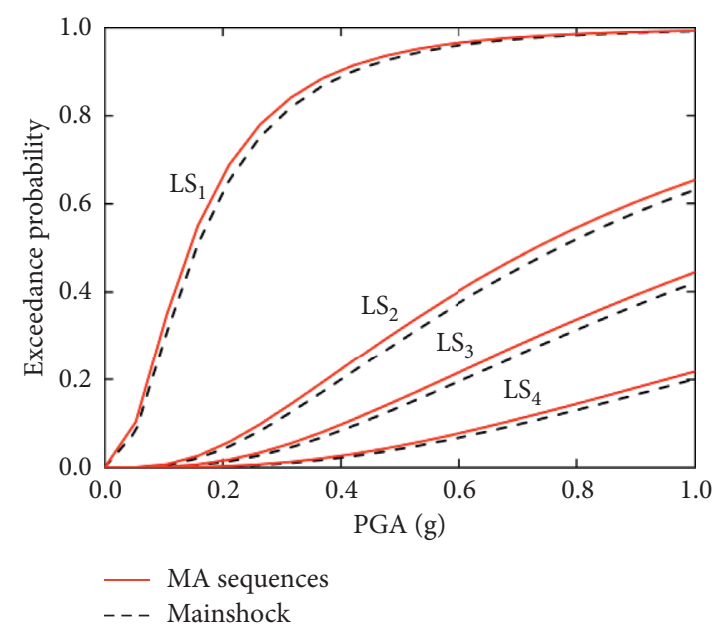

(b)

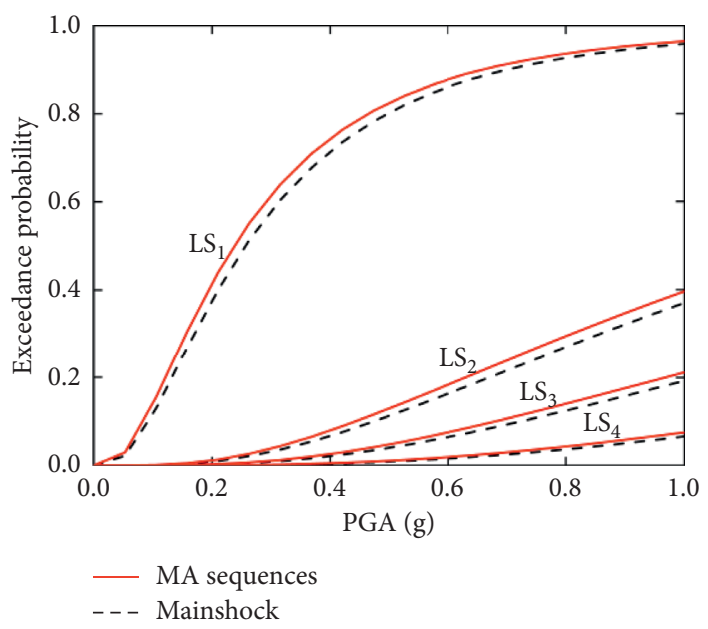

(c)

Figure 10: Vulnerability curves. (a) $1^{\#}$ bearing. (b) $2^{\#}$ bearing. (c) $4^{\#}$ bearing.

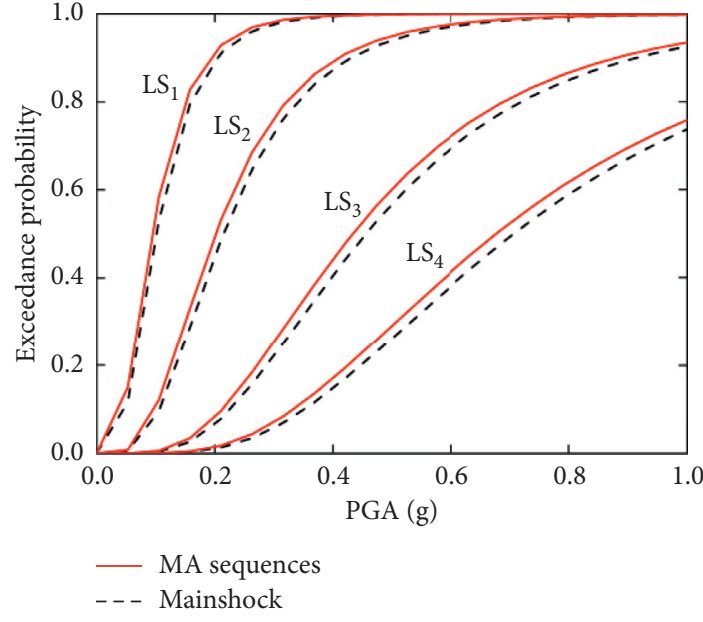

(a)

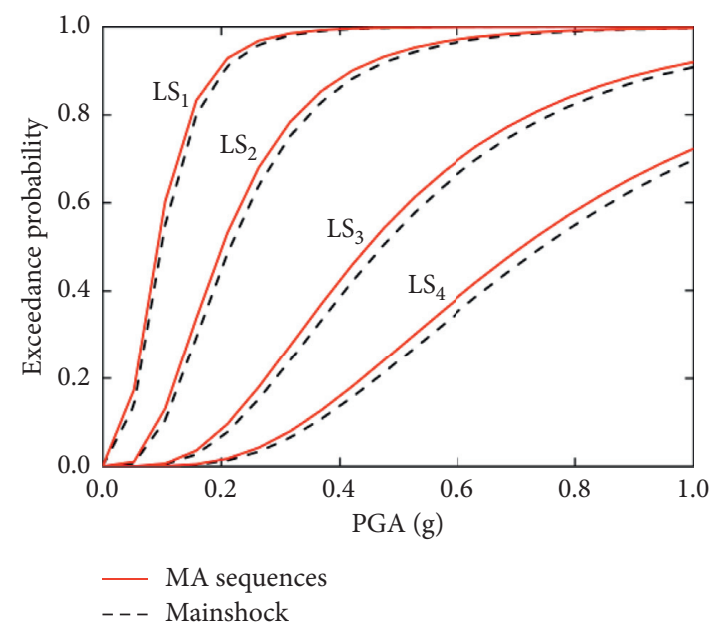

(b)

FIgURE 11: Vulnerability curves. (a) Left abutment. (b) Right abutment. 


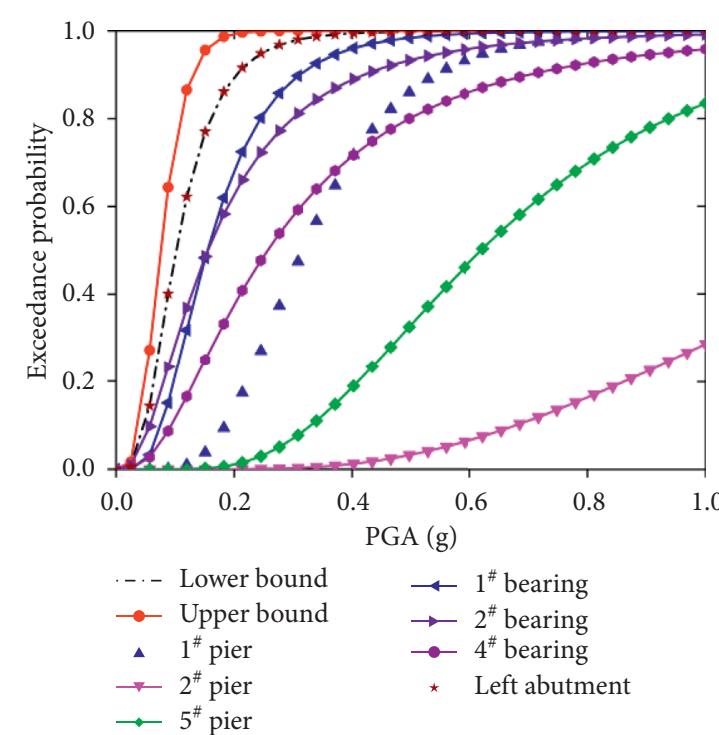

(a)

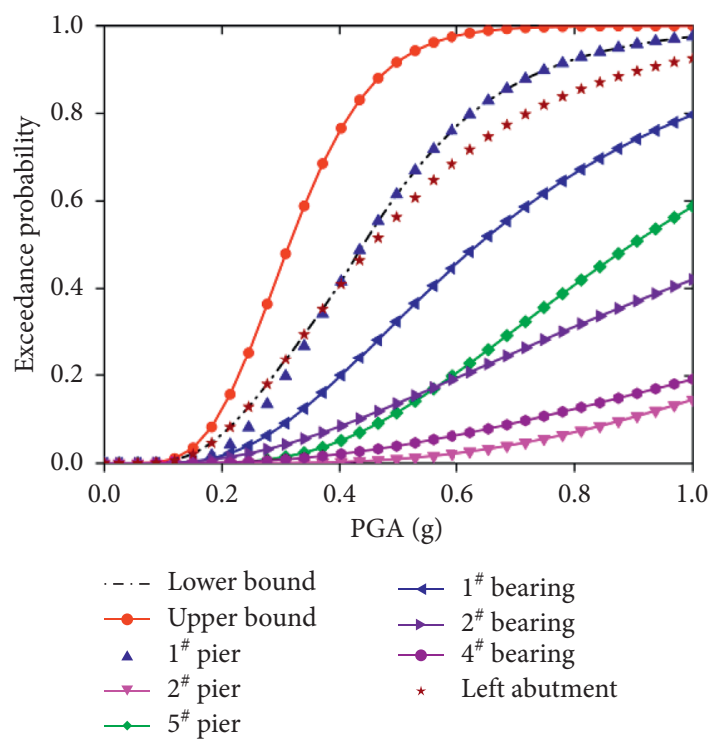

(c)

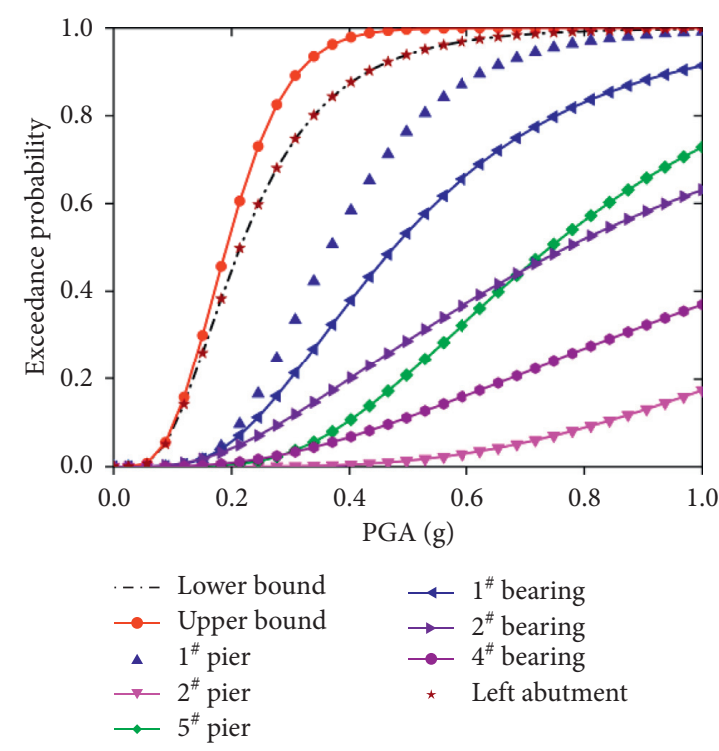

(b)

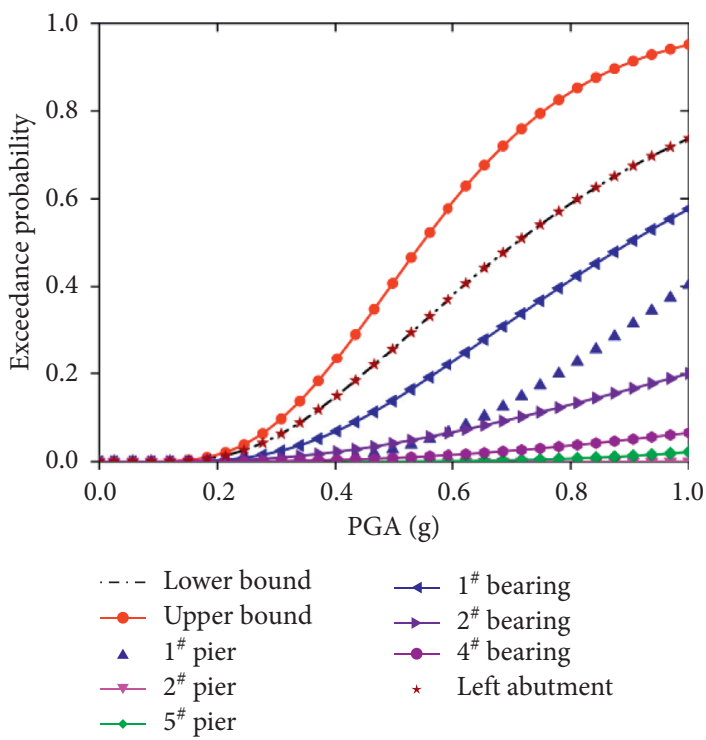

(d)

Figure 12: Vulnerability curves for the bridge components and system. (a) Slight damage. (b) Moderate damage. (c) Extensive damage. (d) Complete damage.

\section{Seismic Vulnerability Analysis of Bridge System}

Bridge is a complex system composed of interconnected and interacting components, and all components are likely to be damaged under earthquake. The seismic vulnerability curves for bridge components can directly reflect the exceedance probability of each component under earthquake, which can provide reference for the reinforcement decision of the entire bridge. However, the exceedance probability of a bridge system is larger than that of a single component under earthquake [23]. If the exceedance probability of a single component is expressed as the failure probability of the bridge system, the seismic capacity of structure will be overestimated. Therefore, the seismic vulnerability of bridge system should be analysed.

7.1. First-Order Boundary Estimation Method. A bridge is a complex structure consisting of superstructures, substructures, bearings, and other components. Accurately calculating the failure probability of a bridge under earthquake is difficult. Establishing a reliability model of bridge system on the basis of structural reliability theory is a common practice to obtain the seismic vulnerability curves for a bridge system. Engineering structures can be divided into series and parallel systems in accordance with the relationship between the failure probabilities of the structural components and system. 


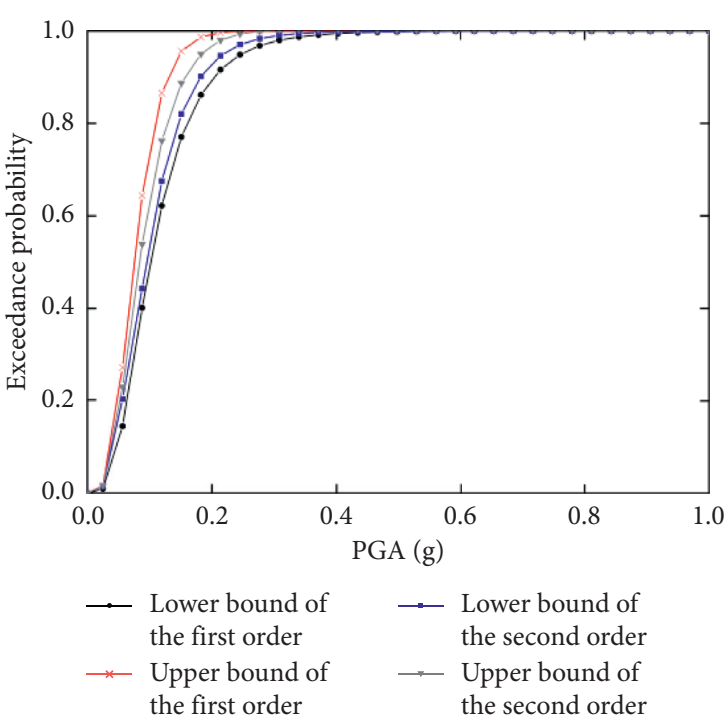

(a)

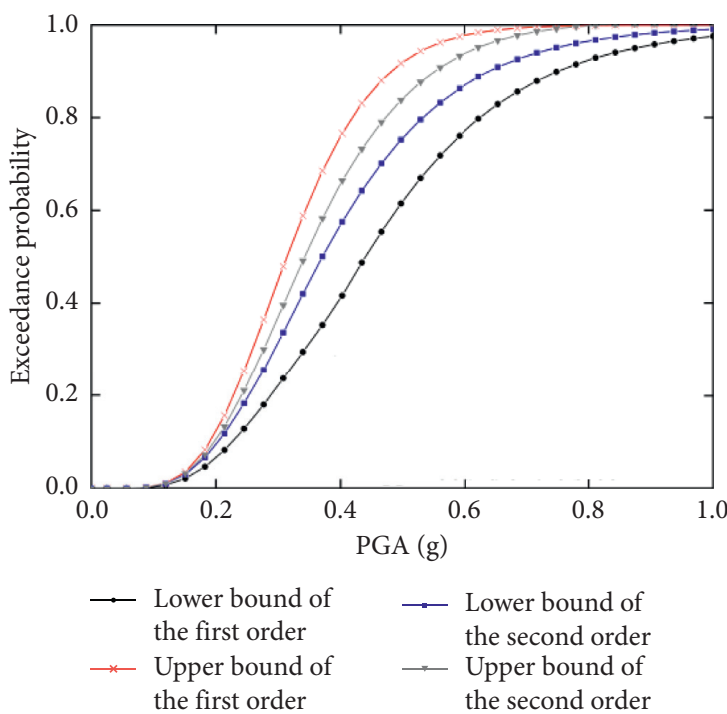

(c)

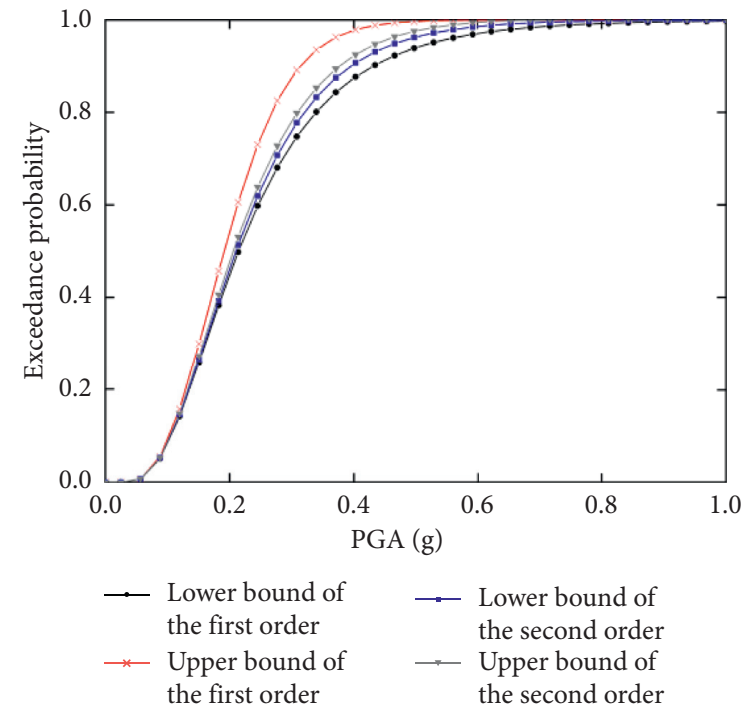

(b)

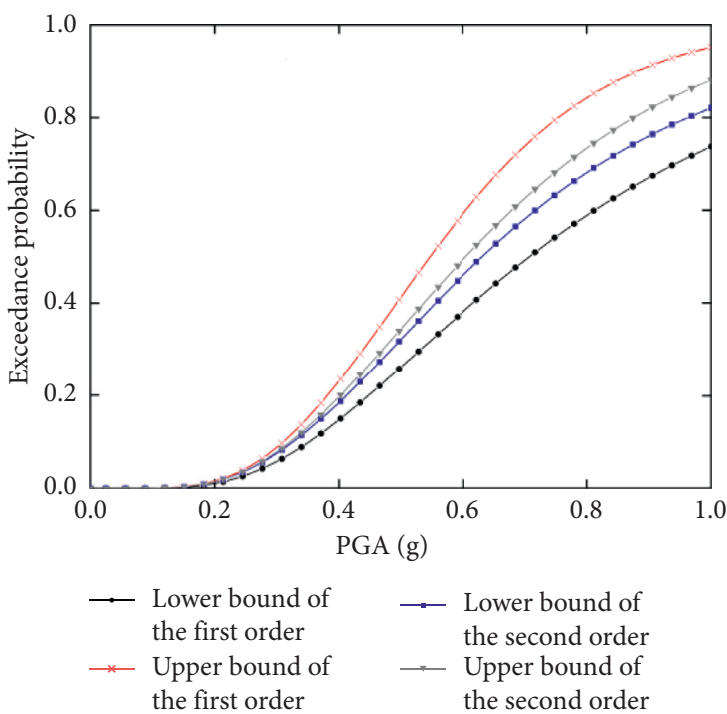

(d)

FIGURE 13: Vulnerability curves for the bridge system based on boundary estimation method. (a) Slight damage. (b) Moderate damage. (c) Extensive damage. (d) Complete damage.

Series system assumes that the structure comprises different components in series, and the importance of each component is the same. If any component of the structure is destroyed, then the structural system is destroyed to the same degree. Parallel system assumes that the structure is composed of different components in parallel; only when all the components of the structure are destroyed is the structural system considered to have the same type of damage. Although deviations exist between the assumption of the two systems and the actual structure, the series model has been widely used in the study of seismic vulnerability of bridges in the past because of the simplicity of the series system.

When the upper and lower bounds of the vulnerability curves for bridge system are determined by the first-order boundary estimation method, each component of bridge is assumed to be independent or completely related to one another [24]. The lower bound indicates that each component has completely positive correlation, and failure of any component will lead to successive failure of other components, whereas the upper bound indicates that each component is independent of one another. The first-order boundary estimation method is a conservative estimation of the failure probability of bridge system which can be defined as

$$
\max _{i=1}^{n}\left[P_{f i}\right] \leq P_{\mathrm{sys}} \leq 1-\prod_{i=1}^{n}\left[1-P_{f i}\right],
$$

where $P_{\text {sys }}$ is the exceedance probability of the bridge system, $P_{f i}$ is the exceedance probability of component $i$, and $n$ is the number of bridge components. 


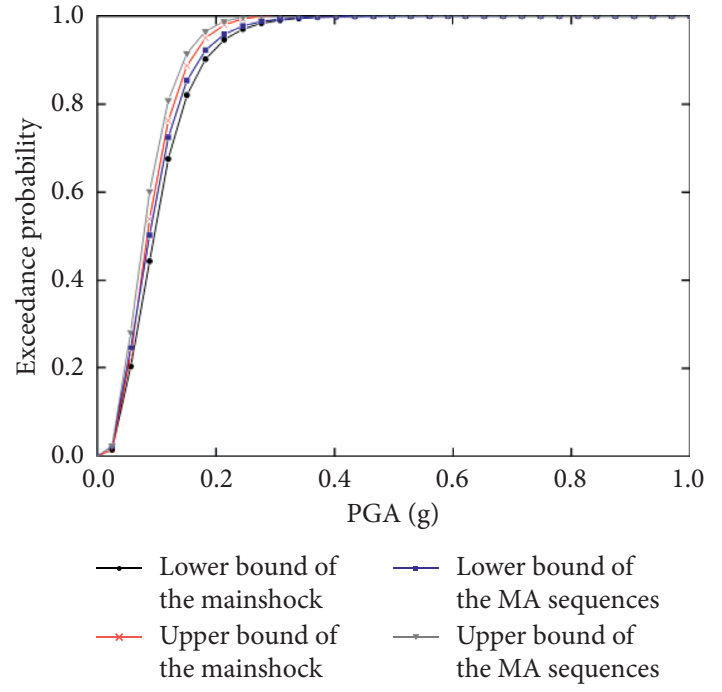

(a)

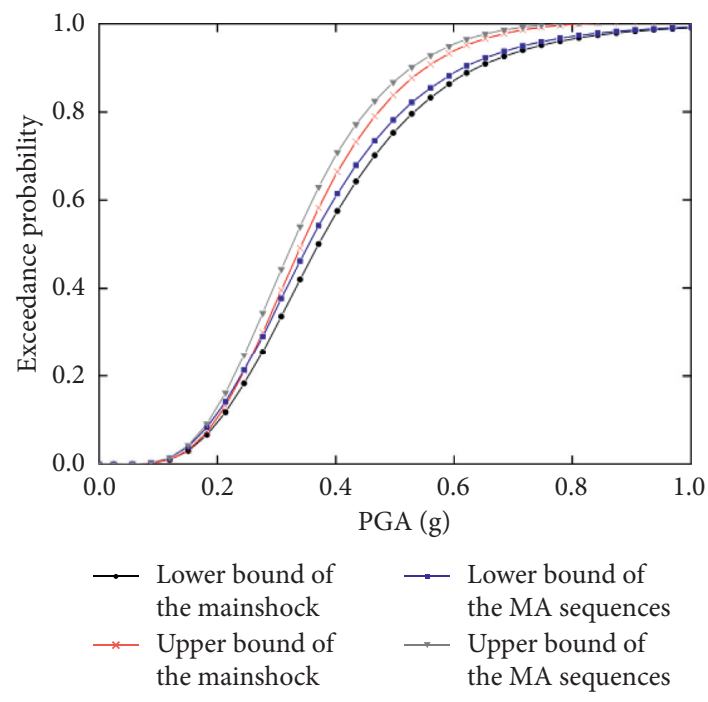

(c)

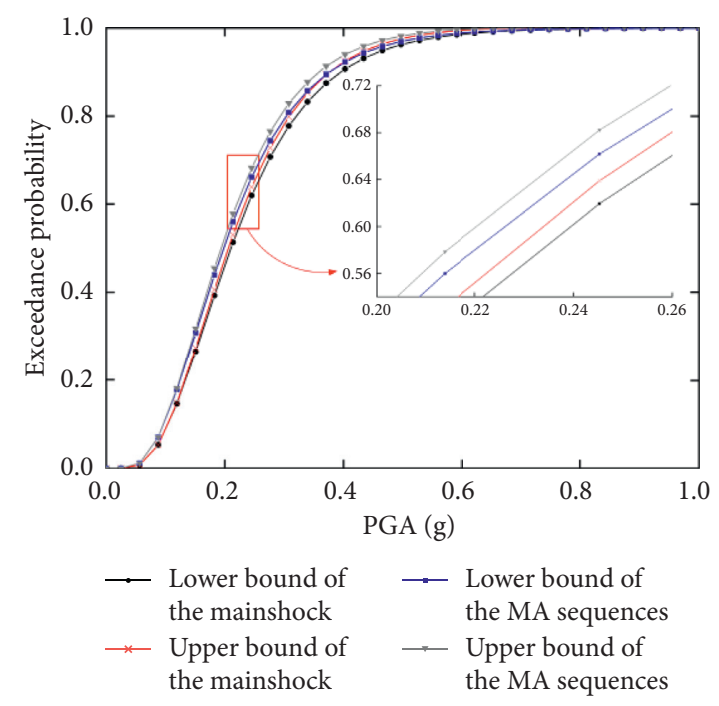

(b)

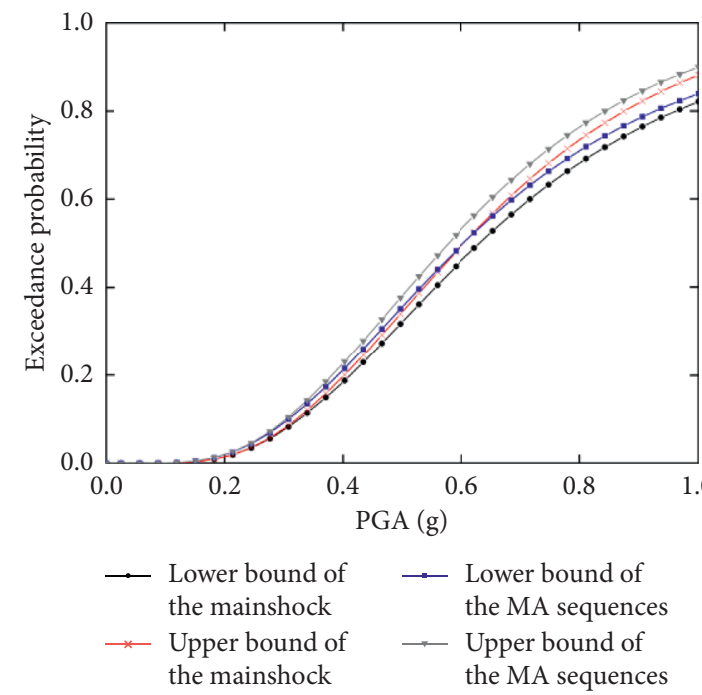

(d)

FIgURE 14: Comparison of vulnerability curves for the bridge system. (a) Slight damage. (b) Moderate damage. (c) Extensive damage. (d) Complete damage.

The vulnerability curves for bridge components under different damage states are compared with those of the bridge system calculated by the first-order boundary estimation method, as shown in Figure 12. Due to the excessive number of bridge components, only representative bridge components are selected for comparison in this study.

Figure 12 shows that, under different damage states, the exceedance probability of the bridge system is higher than that of single component. Using the vulnerability of bridge components to represent the vulnerability of the bridge system will overestimate the seismic performance of the structure, and potential safety hazards exist. The exceedance probability of the bridge system under different damage states increases with the increase in PGA. The exceedance probability of different components varies greatly. The seismic performance of abutments on both sides, $1^{\#}$ pier and $4^{\#}$ pier and $1^{\#}$ bearing and $5^{\#}$ bearing, is poor, and the probability of damage under earthquake is high. The upper and lower boundary widths of the vulnerability curves for the bridge system obtained by the first-order boundary estimation method gradually increase with the progressive increase in the damage state. When evaluating the seismic performance of a bridge, the failure probability of the bridge system cannot be accurately evaluated.

7.2. Second-Order Boundary Estimation Method. As for the bridge system, all the components of the bridge are assumed to be completely related or independent, which will lead to the failure probability width being excessively wide and inconsistent with the actual situation. Hunter [25] proposed an overall structure exceedance probability method considering the correlation among different components, as follows: 


$$
\begin{aligned}
& \rho_{i j}=\frac{\operatorname{Cov}\left(X_{i}, X_{j}\right)}{\sigma_{X i}, \sigma_{X j}} \\
& P_{f 1}+\sum_{i=2}^{n} \max \left(P_{f i}-\sum_{j=1}^{i-1} P_{f i j}, 0\right) \leq P_{s y s} \leq \sum_{i=1}^{n} P_{f i}-\sum_{i=2}^{n} \max _{j<i}\left(P_{f i j}\right),
\end{aligned}
$$

where $\rho_{i j}$ is the correlation coefficient between components $i$ and $j ; X_{i}$ and $X_{j}$ are the seismic demands of components $i$ and $j$, respectively; $\operatorname{Cov}\left(X_{i}, X_{j}\right)$ is the covariance; $\sigma_{X i}$ and $\sigma_{X j}$ are the standard deviations of $X_{i}$ and $X_{j}$, respectively; $P_{f 1}$ is the exceedance probability of the most vulnerable component in all components; $P_{f i}$ is the exceedance probability of component $i$; and $P_{f i j}$ is the exceedance probability of components $i$ and $j$ being destroyed simultaneously.

The vulnerability curves for the bridge system under different damage states are calculated by the second-order boundary estimation method, as shown in Figure 13. The vulnerability curves for the system calculated on the basis of the first-order boundary estimation method are also provided for the convenience of comparison.

Figure 13 demonstrates that the upper and lower boundary widths of the vulnerability curves for the bridge system calculated by the second-order boundary estimation method are significantly reduced compared with the vulnerability curves calculated by the first-order boundary estimation method. When PGA is equal to 0.4 , the upper and lower boundary widths are reduced from $0.5 \%$ to $0.2 \%$ in slight damage state, from $10.2 \%$ to $1.8 \%$ in moderate damage state, from $35.0 \%$ to $8.9 \%$ in extensive damage state, and from $8.6 \%$ to $1.3 \%$ in complete damage state. Under the four damage states, the boundary widths are decreased by $60 \%$, $82 \%, 75 \%$, and $85 \%$.

The vulnerability curves for the bridge system subjected to mainshock and MA sequences are calculated using the secondorder boundary estimation method, as shown in Figure 14.

Figure 14 presents that the exceedance probabilities of the vulnerability curves for the bridge system subjected to MA sequences are significantly higher than those only considering the mainshock. When PGA is equal to 0.2, the upper and lower limit values of exceedance probability are increased by $1.1 \%$ and $1.6 \%$, respectively, in the slight damage state: by $10.1 \%$ and $10.1 \%$, respectively, in the moderate damage state; by $23.9 \%$ and $22.0 \%$, respectively, in the extensive damage state; and by $35.3 \%$ and $34.9 \%$, respectively, in the complete damage state. In summary, strong aftershocks will cause secondary damage to damaged bridges after mainshock, and the exceedance probability of the bridge system will considerably increase. The influence of aftershocks on structure should be considered when evaluating the seismic performance of bridges; otherwise, the seismic performance of structures will be overestimated, and potential safety hazards will occur.

\section{Conclusions}

The seismic vulnerability of multispan continuous bridge components subjected to MA sequences and mainshock is analysed in this study by generating the MA sequences. On the basis of structural reliability theory, the vulnerability curves for the bridge system subjected to MA sequences and mainshock are established using first- and second-order boundary estimation methods, respectively. The main conclusions are as follows:

(1) The exceedance probability of the bridge components and system subjected to MA sequences and mainshock increases with the PGA. For any given PGA, the exceedance probability decreases with the increase in damage degree.

(2) The exceedance probability of the bridge components and system subjected to MA sequences is significantly higher than that under the consideration of mainshock only. The exceedance probability increases gradually with the deepening of damage degree. In the state of slight damage, the structural seismic response is maintained within the elastic range, and the secondary damage caused by aftershocks to the bridge is insignificant; in the state of extensive and complete damage, the secondary damage caused by aftershocks to the damaged structure is relatively significant.

(3) Under the same PGA and damage state, the exceedance probability of the bridge system is higher than that of any component. When evaluating the seismic performance of the bridge system, the vulnerability curves for the bridge system must not be replaced with the vulnerability curves for components; otherwise, the seismic performance of the structure will be overestimated, and potential safety hazards will occur.

(4) The first-order boundary estimation method cannot consider the correlation of components. The calculated upper and lower limit widths of the vulnerability curves for the bridge system are large, especially in extensive and complete damage. The second-order boundary estimation method based on component correlation coefficient calculation can significantly reduce the upper and lower limit widths of the vulnerability curve and improve the calculation accuracy.

\section{Data Availability}

The data used to support the findings of this study are available from the corresponding author upon request.

\section{Conflicts of Interest}

The authors declare that there are no conflicts of interest regarding the publication of this paper.

\section{Acknowledgments}

This research was supported by the National Natural Science Foundation of China (Grant no. 51608488) and Scientific 
and Technological Project of Henan Province, China (192102210185).

\section{References}

[1] E. Choi, R. DesRoches, and B. Nielson, "Seismic fragility of typical bridges in moderate seismic zones," Engineering Structures, vol. 26, no. 2, pp. 187-199, 2004.

[2] C. Amadio, M. Fragiacomo, and S. Rajgelj, "The effects of repeated earthquake ground motions on the non-linear response of SDOF systems," Earthquake Engineering \& Structural Dynamics, vol. 32, no. 2, pp. 291-308, 2003.

[3] L. Q. Xie, J. Wu, and Q. Huang, "Analysis of the seismic demand of high-performance buckling-restrained braces under a strong earthquake and its aftershocks," Advances in Civil Engineering, vol. 2019, Article ID 1482736, 14 pages, 2019.

[4] J.-S. Jeon, R. DesRoches, and D. H. Lee, "Post-repair effect of column jackets on aftershock fragilities of damaged RC bridges subjected to successive earthquakes," Earthquake Engineering \& Structural Dynamics, vol. 45, no. 7, pp. 1149$1168,2016$.

[5] D. Vamvatsikos and C. A. Cornell, "Incremental dynamic analysis," Earthquake Engineering \& Structural Dynamics, vol. 31, no. 3, pp. 491-514, 2002.

[6] S. Hu, Seismic fragility assessment and seismic retrofit scheme of bridges considering chloride attack, Ph.D. thesis, Hunan University, Changsha, China, 2011.

[7] X.-G. Zeng, S.-F. Jiang, X.-C. Xu, and H.-S. Huang, "Numerical modeling of earthquake-damaged circular bridge columns repaired using combination of near-surfacemounted BFRP bars with external BFRP sheets jacketing," Materials, vol. 12, no. 2, p. 258, 2019.

[8] J. M. Duncan and R. L. Mokwa, "Passive earth pressures: theories and tests," Journal of Geotechnical and Geoenvironmental Engineering, vol. 127, no. 3, pp. 248-257, 2001.

[9] Y. Hose, P. Silva, and F. Seible, "Development of a performance evaluation database for concrete bridge components and systems under simulated seismic loads," Earthquake Spectra, vol. 16, no. 2, pp. 413-442, 2000.

[10] S. Masanobu, M. Q. Feng, and L. Jongheon, "Statistical analysis of fragility curves," Journal of Engineering Mechanics, vol. 126, no. 12, pp. 1224-1231, 2000.

[11] B. G. Nielson, Analytical fragility curves for highway bridges in moderate seismic zones, Ph.D. thesis, University of Georgia Institute of Technology, Atlanta, GA, USA, 2005.

[12] J. Zhang and Y. Huo, "Evaluating effectiveness and optimum design of isolation devices for highway bridges using the fragility function method," Engineering Structures, vol. 31, no. 8, pp. 1648-1660, 2009.

[13] Y. J. Park and A. H. S. Ang, "Mechanistic seismic damage model for reinforced concrete," Journal of Structural Engineering, vol. 111, no. 4, pp. 722-739, 1985.

[14] L. Jiang, J. Zhong, and M. He, "Optimal seismic intensity measure selection for isolated bridges under pulse-like ground motions," Advances in Civil Engineering, vol. 2019, Article ID 3858457, 22 pages, 2019.

[15] J. Zhong, J. S. Jeon, and Y. H. Shao, "Optimal intensity measures in probabilistic seismic demand models of cablestayed bridges subjected to pulse-like ground motions," Journal of Bridge Engineering, vol. 24, no. 2, Article ID 04018118, 2019.

[16] G. D. Hatzigeorgiou and D. E. Beskos, "Inelastic displacement ratios for SDOF structures subjected to repeated earthquakes," Engineering Structures, vol. 31, no. 11, pp. 2744-2755, 2009.

[17] R. K. S. Chouhan and V. K. Srivastava, "Global variation of $b$ in the gutenberg richter's relation $\log N=a-b M$ with depth," Pure and Applied Geophysics PAGEOPH, vol. 82, no. 1, pp. 124-132, 1970.

[18] B. Panchireddi and J. Ghosh, "Cumulative vulnerability assessment of highway bridges considering corrosion deterioration and repeated earthquake events," Bulletin of Earthquake Engineering, vol. 17, no. 3, pp. 1603-1638, 2019.

[19] S. Mangalathu, E. Choi, and H. C. Park, "Probabilistic seismic vulnerability assessment of tall horizontally curved concrete bridges in California," Journal of Performance of Constructed Facilities, vol. 32, no. 6, Article ID 04018080, 2018.

[20] K. Ramanathan, R. DesRoches, and J. E. Padgett, "A comparison of pre- and post-seismic design considerations in moderate seismic zones through the fragility assessment of multispan bridge classes," Engineering Structures, vol. 45, pp. 559-573, 2012.

[21] C. A. Cornell, F. Jalayer, R. O. Hamburger, and D. A. Foutch, "Probabilistic basis for 2000 SAC Federal Emergency Management Agency steel moment frame guidelines," Journal of Structural Engineering, vol. 128, no. 4, pp. 526-533, 2002.

[22] Federal Emergency Management Agency, HAZUS99 User's Manual, Federal Emergency Management Agency, Washington, DC, USA, 1999.

[23] B. G. Nielson and R. DesRoches, "Seismic fragility methodology for highway bridges using a component level approach," Earthquake Engineering \& Structural Dynamics, vol. 36, no. 6, pp. 823-839, 2007.

[24] L. Li, S. Hu, and L. Wang, "Seismic fragility assessment of a multi-span cable-stayed bridge with tall piers," Bulletin of Earthquake Engineering, vol. 15, no. 9, pp. 3727-3745, 2017.

[25] D. Hunter, "An upper bound for the probability of a union," Journal of Applied Probability, vol. 13, no. 3, pp. 579-603, 1976. 